\title{
Introduction to the Handbook on Cities and Complexity \\ Juval Portugali
}

Past decades have witnessed two interrelated developments: the emergence of general theories of complex self-organized systems; and the consequent emergence of complexity theories of cities (CTC), a domain of research that applies the various complexity theories to the study of cities. From a small stream of studies that started at end of 1970, CTC evolved to its current position as a dominant approach to urban dynamics, planning and design. The five parts of Handbook on Cities and Complexity comprising 19 chapters, on the one hand, follow this development while, on the other, provide a snapshot of the state of the art of CTC at the beginning of 2021. The list of contributors to this volume includes Hermann Haken, who is one of the founders of general complexity theory, founders of the domain of CTC, as well as the younger generations of scholars of cities as complex systems. The structure of the handbook commences with foundations (Part I), continues with reviews of the leading CTC (Part II), and the links between complexity, languages and cities (Part III), to modelling approaches (Part IV) and, finally, to urban planning and design (Part V). The book concludes with an Epilogue on 'Cities and complexity in the time of COVID-19', a topic that was always 'in the air' while the various contributions to this handbook were written, yet was not explicitly discussed in the various chapters. Ten of the authors volunteered to write short notes about this issue, related to their specific topics and personal experiences.

\section{PART I: FOUNDATIONS}

Part I starts with my overview, in Chapter 1, of the evolving perception of the general notions of a complex system and complex adaptive systems (CAS), and the ways they were applied to the domain of CTC. As detailed by Hermann Haken in Chapter 2, the founding complexity theories originated in the material sciences from scientists who revealed that in particular situations (for example, Bénard focuses on instability and the phenomenon of laser) inanimate matter exhibits properties commonly attributed to the domains of life such as history, evolution, unpredictability, irreversibility, nonlinearity, uncertainty and so on (Portugali 1985). At a later stage, as theories of complexity and selforganization were explicitly applied to several domains of life, a new property entered the vocabulary of complexity: adaptation - cities as complex systems were now perceived as CAS - complex adaptive systems. The 'beyond' in the title of Chapter 1 ('Cities, complexity and beyond'), indicates, first, that cities as complex systems have their own uniqueness: beyond being CAS, they are hybrid complex systems composed of artifacts, which are simple systems, and urban agents, which are complex systems. Secondly, in order to understand the behavior of the urban agents, a link should be made to the cognitive sciences. 


\section{Handbook on cities and complexity}

Thirdly, the application of complexity theories to the study of cities entailed two potentials: (1) to reformulate a 'new science of cities' on the basis of the plethora of quantitative methods and modelling approaches offered by the theories of complexity - this potential was fully realized; and (2) to bridge the century-old gap between the quantitative and the hermeneutic traditions in the study of cities - this potential has yet to be realized.

Chapter 2, by Hermann Haken, provides an insider's first-hand view on 'The emergence of complexity theories: an outline'. Haken is the founder of the theory of synergetics, one of the cornerstones of the general theory of complexity. The notion of 'emergence' entails the impression of a sudden appearance. However, in this chapter, Haken shows how complexity, self-organization, fractals, phase transition, and other notions and properties of complexity theory evolved as a logical consequence of the long history of ongoing discourse in the domain of physics.

For Haken (as for many others) physics functions also as a paradigm for science at large owing to its ability to link 'the abstract world of ideas including mathematics and the concrete world in the form of matter'. As he demonstrates, it was specifically thermodynamics (the branch of physics that deals with heat, work and temperature, and their relationship to energy, radiation and the physical properties of matter) that has played a crucial role in the development of complexity theories. In particular, the notions of free energy and entropy were dominant in the early formulations of complexity theory. Collective phenomena in physics (for example, ice into water, ferromagnetism and superconductivity) have paved the way for notions such as phase transition and steady state, and the relationship between part-whole in complex systems, while the chaos theory of complexity has its origin in the studies of Henri Poincare (1854-1912) on the problem of the stability of the solar system. Also, for Prigogine, the prototypical example for his dissipative structures was the Bénard instability (Bénard 1900).

Haken then describes, in some detail, synergetics - his theory of complexity; its emergence in connection with the laser device, that is, the laser paradigm that forms synergetics' canonical experiment (based on the process of stimulated emission first introduced by Einstein in 1917). Then Haken discusses synergetics' first foundation as a bottom-up microscopic approach and, later, the second foundation of synergetics as a top-down approach related to information theory. Finally, the notions of Friston's (2010) free energy principle and game theory and their relationship to synergetics are discussed.

Similarly to the general theories of complexity, the current view of cities as complex systems has deep historical roots. As shown in Chapter 3 by Michael Batty, one of the founders of the domain of CTC, the current view has its origin in what Bertallanffy (1968) formulated as general system theory. To this I would add that the view of cities as systems was implicit in the writings of some early twentieth-century studies (for example, Auerbach 1913; Christaller 1933 [1966]) and explicit in works such as Mcloughlin's (1969) Urban and Regional Planning: A System Approach or Chadwick's (1978) A System View of Planning. Batty mentions the, now classic, studies of Alexander's (1965) 'A city is not a tree' and Jacob's (1961) The Death and Life of Great American Cities as forerunners of CTC, which indeed they were (compare Chapter 11 in this volume).

Adopting Weaver's (1948) terminology in 'Science of complexity', Batty refers to the past 60 years of evolving ideas about cities as increasing realization that 'our city systems are complex': first, cities were perceived as simple systems, then as systems of disorganized complexity and, currently, as systems of organized complexity. From this 
perspective he returns to some of the classic properties of cities identified since the early twentieth century: the rank size rule, central places hierarchies and gravity-interaction models. By re-interpreting these in relation to current urban scaling, allometry and fractals, he shows them to be aspects of the general property of cities as complex systems, conceptually as well as mathematically. As systems of organized complexity, cities are characterized by unpredictability; thus, suggests Batty, although we cannot predict the future, we can still invent it. 'What all this means', he concludes, 'is that in thinking about how our cities function and evolve, we face a barrier of predictability that suggests that our theories can only ever be used to inform our understanding, never to be able to predict the future, only to explore it.'

Similarly to many concepts in science (for example, chaos, catastrophe and energy), the notion of complexity is used in ordinary language to convey a meaning that is not necessarily identical with its usage in the context of science. Chapter 4, by Stephen Marshall and Nick Green, looks at complexity from an ordinary language usage of the term, and thus from the way it was used and understood over time and in the study of cities prior to the emergence of complexity theory and CTC - an approach that takes in a broad sweep of history, ending in the 1990s, when complexity studies of cities started to take off. Borrowing John Maynard Smith's notion of 'major transitions' (Smith and Szathmary 1997), Marshall and Green propose six major transitions that paved the way for the penetration of complexity into the discourse on cities and to its current position in the discourse on cities, planning and design.

The first two transitions are grand transformations of world view: Newton's clockwork universe and Darwin's evolution with a world view that 'all living things are related to each other' (Chapter 4 in this volume), which influenced cities through the work of Patrick Geddes (1915). For Geddes, cities and their planning were perceived as part of the evolution of Homo sapiens in its increasingly artificial environment. The remaining four transformations are all in the realm of cities. The third transformation is Jacobs's (1961) 'The kind of problem a city is', which was based on Weaver's (1948) notion of organized complexity and Alexander's (1965) 'A city is not a tree', suggesting a deep, complex and functional order beneath the seemingly chaotic appearance of cities. The fourth transition brought to the fore social life, namely, beneath the seemingly chaotic appearance of poorer areas there exists a deep, complex and functional social order. The fifth transition followed recognition that the story of cities and planning is told and implemented from a very specific perspective, that of the Western male culture and point of view. Finally, the sixth transition brings us on to the path towards CTC; following recognition of the wicked nature of urban reality, the humanistic and structuralist-Marxist criticisms, approaches such as collaborative planning eventually paved the way for CTC.

\section{PART II: COMPLEXITY THEORIES OF CITIES}

All theories of complexity were applied to the study of cities giving rise to the domain of CTC. Similarly to the general complexity theories, each CTC sheds light on specific aspect of cities as complex systems. Part II describes some of the leading CTC applications, from their start in the 1970s to their state at end of 2020. Of special influence on the study of cities were/are two leading schools of complexity theory, one led by Ilya 


\section{Handbook on cities and complexity}

Prigogine whose starting point was chemical kinetics with special emphasis on the notion of time, the other led by physicist and mathematician Herman Haken who, as we have seen in respect of Chapter 2 and see again in relation to Chapter 6, started with the phenomenon of laser.

In Chapter 5, Peter M. Allen opens his discussion on the evolution of cities with Prigogine's notion of dissipative structures and his theoretical model, the Brusselator, which enables the study of phenomena of symmetry breaking and self-organization (Nicolis and Progogine 1977). From this vantage point, Allen explores different types of environmental and urban simulation models, and the way they treat the relationships between bottom-up and top-down processes that typify the dynamics of cities. Allen shows that model building is 'an unending process' since models as interpretive frameworks are always imperfect and so is our understanding of cities as complex systems: "There is no perfect ultimate "solution" to which we are tending! Life will always possess multiple pathways into the future.'

Next, in Chapter 6, Juval Portugali and Hermann Haken develop the notion of 'Synergetic cities', which started by applying the various aspects of synergetics (compare Chapter 2 in this volume) to cities and continued by elaborating new conceptual and theoretical frameworks that reflect, and are a consequence of, the specific properties of cities, namely, that they are hybrid complex systems (Haken and Portugali 2021). Accordingly, the first part of this chapter introduces synergetics, and its basic paradigms and the way they were applied to cities, while the second part introduces the notions of synergetic inter-representation networks (SIRN), information adaptation (IA) and their conjunction, SIRNIA, as the theoretical foundation for the study of cities as hybrid complex systems. This theoretical discussion is followed and illustrated by three case studies. Finally, the notions of steady state, phase transition and slaving are introduced, and their role in cities is elaborated theoretically and empirically.

'I choose to enter through an object - system of cities - and a discipline - geography' writes Denise Pumain in her abstract to Chapter 7 in a very personal account of cities and complexity. Two interrelated principles stand at the core of her discussion. The first, the title of her chapter 'Co-evolution as the secret of urban complexity', comes to solve the paradox that, despite the changes that cities undergo, 'we observe a very large persistency in the relative positions of cities in the hierarchy of sizes over long time periods'. The second is the spiral construction of knowledge (Pumain 2009), showing that our current knowledge of cities as complex systems has its roots in past conceptions of cities, for example, in the writing of 'Saint-Simonian engineer Jean Reynaud describes as early as 1841' (Reynaud 1841) and decades later in studies such as Auerbach's (1913) rank size rule and Christaller's (1933 [1966]) central place theory.

Of all theories of complexity, fractal geometry is visually the most beautiful. In Chapter 8, Pierre Frankhauser introduces step by step the fractal approaches to cities. He starts by demonstrating the fractal properties that can be observed in the morphology of cities, and continues by employing the Sierpinski carpets class of fractals as a means to model and generate morphologies identical to urban morphologies. He then explores the potential and usefulness of the multifractal approach to deal with the irregularities of urban patterns. These explorations led Frankhauser to develop a software package, Fractalopolis, a planning tool capable of supporting the design of a multifractal plan for an urban region and assessment of the suitability of developing each part of the region. 
Chapter 9, by Yanguang Chen, provides a discussion about the inherent relationships between the theories of scaling, fractals and the complexity of cities, with special emphasis on their spatiality. While each of the three theories have already been referred to in previous chapters, here the focus is on their integration as aspect, properties and methodologies of cities as complex systems. Based on mathematical reasoning and empirical findings, the chapter first introduces scaling and its applications to or implications for cities, then it introduces fractals and multifractals in general and in the context of cities, and finally focuses on complexity and the way to explore the spatial complexity of cities in relation to fractals, multifractals and scaling.

Cybernetics; or, Control and Communication in the Animal and the Machine by Norbert Wiener (1948) can be regarded as one of the earliest theories of systems and complexity. Yet, in Chapter 10, Carlos Gershenson, Paolo Santi and Carlo Ratti reiterate the old concept in the context of the current futuristic discussions regarding cities; that is, building 'cybernetic cities' in which advanced information and communication technologies (ICT) will replace humans' urban control loop (composed of information, algorithms and agents). The chapter then discusses the new smart technologies of information, algorithms and agents. The big questions that these smart cybernetic cities pose are, 'If we manage to develop [technologically smart] information, algorithms and agents, and integrate them to solve an urban problem, what would be the outcome? What is the benefit of having cybernetic urban systems?' Interestingly, there are no smart devices that can answer these questions.

\section{PART III: COMPLEXITY, LANGUAGE AND CITIES}

The dyad of language-city has a long history in the study of cities, usually when using language or lexical elements metaphorically in order to describe and understand cities, or vice versa, when inferring from cities to languages. 'Our languages' wrote Wittgenstein (1953) 'can be seen as an ancient city: a maze of little streets and squares, of old and new houses' (compare Chapter 19 in this volume). Another example is Lynch's (1960, p. 2) notion of legibility as 'the apparent clarity . . of the cityscape'. The scientific projects of Christopher Alexander with the centrality of his A Pattern Language (Alexander et al. 1977) and of Bill Hillier's (1996) space syntax, suggest moving beyond the metaphoric relations, namely, that there is literally a language of cities with its specific syntax, semantics, pragmatics and the rest. As shown in Chapter 19 of this volume, Alexander explicitly compares his pattern language with natural spoken language.

The triad of complexity-language-city follows on from the synergetic cities view (Chapters 1, 2 and 6 in this volume). One of Haken's central ways to convey the notions of an order parameter and the slaving principle that stands at the core of his theory of synergetics, is by reference to language. Languages emerge out of the interaction between the parts (people) as order parameters, but once they come into being they describe and prescribe (enslave) the behavior of the parts, and so on in circular causality. A similar process takes place in cities. They come into being out of the interaction between the parts - the urban agents - but once they come into being they describe and prescribe (enslave) the behavior of the urban agents, and so on in circular causality. 
As noted previously, Alexander's 'A city is not a tree', written at an early stage of his career, is considered a forerunner to the complexity view on cities. For some reason the rest of his life-work has little or no echo in CTC discourse and writing, not even his 2003 paper with its long and informative title that explicitly addresses the relationships between the four volumes of his The Nature of Order (Alexander 2002-04) and complexity: 'New concepts in complexity theory arising from studies in the field of architecture: an overview of the four books of the nature of order with emphasis on the scientific problems which are raised'. Chapter 11 by Christopher Alexander puts this forgotten paper squarely in the context of our cities and complexity.

As we have seen from the chapters in Parts I and II, the various complexity theories originated in the hard sciences, such as physics and chemistry, with close association to thermodynamics, then at a later stage were applied to, that is informed, the domain of cities, giving rise to CTC. Alexander suggests a view that diametrically opposes this path, namely, that the study of architecture as he developed it in his four volumes, The Nature of Order, should instead inform the sciences in general and thus the science of complexity including CTC. Properties such as value, aesthetics, beauty and wholeness, which throughout most of the twentieth century were expelled from science on the grounds that they are subjective, form according to Alexander, the core of the practice of architecture and should also form the bases of the current science of complexity; in general and in connection with architecture, cities' urban planning and design. In Chapter 11 he develops this view step by step, starting with the notions of 'wholeness and value as a necessary part of any complex system', through recursive processes, measures of coherence, the links to cognition, aspects of subjectivity, symmetries and sub-symmetries, adaptations, structure preserving transformations and concluding with the role of beauty in the science of complexity. At the core of Alexander's view on complexity are 15 properties associated with 15 transformations. 'I believe', he summarizes, 'the fifteen transformations I have discovered will turn out to be naturally occurring, and necessarily occurring in all complex systems.'

Bill Hillier started to develop his space syntax in the 1970s with no explicit links to CTC which started to emerge at the same time. These links were explicated later out of the recognition that language and complexity are interwoven (for example, Hillier 2009). In that paper (Hillier 2009), he notes the absence of formal language that differentiates between one form of complexity and another with the required rigor and consistency. He continues by writing that space syntax research about cities is seeking to redress the balance. When I started to work on this handbook, he and I were corresponding. He suggested writing a chapter to extend the arguments proposed in his 2009 paper 'The city as a socio-technical system'. Sadly, Bill Hillier passed away on the 5 November 2019. Alan Penn, who was working closely with Hillier for many years, agreed to write the chapter in his stead.

Chapter 12, by Alan Penn, is thus in part a memorial to Bill Hillier and his space syntax theory, and in part Penn's specific perspective on space syntax, complexity and the city. Penn first introduces space syntax theory in itself and in connection with complexity science and CTC. Next, he adds his own perspective, which centers around the notion of empathy (among other things) as it entailed the evolving relationship between the architectural construction of pre-urban and urban settlements. He emphasizes that 'while space syntax bears a relationship to complexity, its prime motivation was not to 
understand complexity per se but to develop a theoretical understanding of the phenomena at hand; of human society, the environments it designs and builds and the interplay between the two'.

\section{PART IV: MODELLING COMPLEX CITIES}

Modelling in general, and urban simulation modelling in relation to cities, is a common way to study complex systems cities. The various complexity theories discussed in Part II include their own modelling approaches. The difference is that Part II formulates a general theory of urban dynamics and then shows how it can be applied to specific case studies, while in Part IV, we start from an urban problem to which an appropriate theory and modelling approaches are then applied. Thus, Chapter 13 by Vincent Verbavatz and Marc Barthelemy commence from an urgent problem: 'traffic congestion is becoming an ever-larger problem'; the challenge is how to mitigate car traffic. To solve this problem, we need an appropriate theory and a modelling approach. They start by critically reviewing studies that have become a paradigm of spatial economics and urban planning, and show that these are empirically based, lacking a theoretical basis. They then develop their own theoretical approach that aims 'to capture the essence of the urban mobility phenomenon'. From this new theoretical vantage point they demonstrate that 'car traffic is governed by three main factors: (1) access to MRT [that is, mass rapid transit], (2) congestion effects, and (3) urban sprawl'. Based on this model, they suggest that in order to reduce car traffic it is necessary to increase access to public transport.

Following the founding studies of Barabási (2002), Watts (2004) and others, the 'new' science of networks that suggests viewing complex systems as networks, was enthusiastically embraced by students of CTC. Cities and systems of cities are essentially complex networks, and so are their sub-systems, such as roads networks. In this context of network analysis and theory, percolation methodology is employed as means to evaluate the structural robustness of networks. In Chapter 14, Nimrod Serok, Orr Levy, Shlomo Havlin and Efrat Blumenfeld Lieberthal start by presenting the specific percolationbased approach they have developed, and then apply it to data on the city centers of London and Tel Aviv in two time frames. Based on the recent availability of big data, they study the interplay between the static road network and the dynamics of the traffic flow on the network. This big data, they suggest, makes it possible to follow in real time the state of traffic in cities and thus to equip planners with an efficient tool to monitor and control that traffic. As a planning tool, their suggested approach 'will bridge the gap between static long-term urban planning and the flexible and dynamic urban rhythm, and will enable planners to keep their role in the formation of better cities'.

Data availability also provides the motivation for Itzhak Benenson and Nir Fulman, in Chapter 15, to apply the knowledge accumulated on the complexity of cities to control specific urban phenomena and problems; in this instance, parking in cities. They show that while the problem of parking is only loosely related to traffic, it is nevertheless typified by some of the main attributes of a complex system, such as non-linearity, emergence and path dependence. However, as the title of their chapter indicates, they suggest that parking is a typical example of 'simple-complex' urban phenomena, namely, cases in which the behavior of the urban agents can be considered simple in that, for example, 


\section{Handbook on cities and complexity}

they are routinized and therefore predictable. Thus, in the context of cities as complex unpredictable systems, we can still identify predictable phenomena - evidently an advantage from the viewpoint of the rational comprehensive planning approach, which is based on predictability. Two notes: first, cities are characterized by long periods of steady state interrupted by short-phase transition events. Thus, at least in retrospect, during their steady state cities are predicted. Second, as noted in several cases (Portugali 2011), it is possible to temporarily close a complex system - for example, a city - and treat it as a simple system (compare also Chapter 16 in this volume).

\section{PART V: COMPLEXITY, PLANNING AND DESIGN}

The emergence of CTC and the realization that cities are complex, self-organized systems entailed a whole set of questions, dilemmas and challenges to the domains of urban planning and design. Of specific importance are the issues of uncertainty and steering, which are discussed in the first two chapters of Part V. Furthermore, the emergence of CTC coincided with significant changes that took place in past decades in the society, politics and planning of democratic societies around the world. The latter entailed the transition from government to governance. The third chapter of Part $\mathrm{V}$ deals with this issue.

Planning and design, as they have evolved throughout the twentieth century, were built on the conviction that science and technology are capable of predicting the future, and if there are difficulties in this task, they are technical matters that will be solved as science and technology progresses. Complexity theories of cities, with their new insight that complexity implies inherent unpredictability and thus uncertainty, created a problem: how to plan toward an unknown future? Chapter 16, by Stefano Moroni and Daniele Chiffi, deals with the relationships between complexity and uncertainty, and the implications thereof to planning. They start by considering a spectrum of certainty, risk, parametric uncertainty and fundamental uncertainty, and concentrate on the latter two forms of uncertainty. They then examine those two forms in two planning situations: first, when the planner has to decide about a given artifact, for example, building a bridge, and second, when the planner has to decide about a regulatory planning policy. Finally, and based on the above, they suggest methodologies to 'cope with different forms of uncertainty by first taking seriously the differences between different decision situations'.

Planning and design, as they have evolved throughout the twentieth century, were also based on the view that their main function is to impose order and organization on the otherwise chaotic urban reality. Complexity theories of cities, with their view that cities are typified by self-organization, entailed a dilemma: if cities self-organize, what is the role of planning and design? Should urban planning strive to steer the self-organized and organizing urban system? If so, how? Chapter 17, by Koen Bandsma, Ward Rauws, and Gert de Roo, suggests the methodology of nudging as a planning instrument capable of influencing the self-organized behavioral pattern of urban agents 'by exploiting the cognitive biases, heuristics and social norms underlying their decision-making'. They start by introducing the general theory of nudging, consider its effectivity in stable-routine versus unstable behavioral pattern in cities' public space, and discuss ethical considerations that should guide governmental planners in their use of this methodology. 
As previously noted, the emergence of CTC coincided with significant changes that took place in the past decades in the society, politics and planning of democratic societies around the world. These changes included processes of privatization that entailed the weakening of the welfare state and the emergence of a third sector of non-governmental organizations (NGOs), also named civil society (a term that has roots in Aristotle's Politics, Hegel, Marx and others). These structural changes show up in the transition from government to governance, that is, the transition of social discourse, politics and planning from a two-sector game (public and private) into a three-sector game (public, private and civil). What are the dynamics of this new urban reality? How are they associated with the dynamics of cities as complex systems, and with urban planning?

Chapter 18, by Sara Encarnação, Fernando P. Santos, Francisco C. Santos, Margarida Pereira, Jorge M. Pacheco and Juval Portugali, employs evolutionary game theory (EGT) as means to respond to this new reality and the questions it entails. The approach is innovative in several respects: it is the first application of EGT to urban planning; it is based on several recent studies that applied EGT to urban dynamics; and, in the context of EGT, it develops a three-sector (populations) game instead of the more common twosector population game. The chapter briefly introduces EGT, its recent applications to the study of cities as complex self-organized systems, and elaborates in some detail its usefulness and potential as a planning tool.

Part V closes with Chapter 19 in which I examine the roots of planning and design through the lens of three aspects of humanity subsumed under three notions: Homo sapience, referring humans' ability to think and act rationally; Henry Bergson's Homo faber, whose core property 'is the faculty of manufacturing artificial objects' (Bergson 1911 [1998], p. 139) and Johan Huizinga's (1949) Homo Ludens (Man the Player). It is shown that the complementarity between these three homos is at the core of human agency - urban agents' capability to manipulate the environment, as well as of chronesthesia (mental time travel) that forms the cognitive basis of planning and design. Agency and chronesthesia are studied from the theoretical perspectives of SIRN, IA and their conjunction SIRNIA, and their role in the dynamics of cities as hybrid complex systems.

\section{EPILOGUE: CITIES AND COMPLEXITY IN THE TIME OF COVID-19}

The various contributions to this handbook were written during the period of COVID-19, a pandemic that came into being and evolved as a typical complex system, exhibiting properties such as abrupt change, non-linearity, unpredictability and uncertainty. Furthermore, the pandemic and cities and urban life coexist in a type of circular causality: on the one hand, cities and urban life had and have important effects on the space-time diffusion of the pandemic, its ups and downs and other properties; on the other, the pandemic affects the dynamics of cities, the opening and closing of businesses, public and private transportation, and urban life in general. In light of the above, and in coordination with Edward Elgar Publishing, each of the contributors was asked (if they had the will and the time) to write a short statement about the pandemic from their chapter topic's viewpoint, as well as from their personal perspective and experience. The authors of ten of the chapters of this handbook agreed to participate and the Epilogue, 
comprising their short statements, represents views and experiences about cities and complexity in the age of COVID-19 at end of November 2020.

The ten short statements appear in the same order as their source chapters, thus representing the five parts of the handbook. What is specifically interesting is that the pandemic is associated with all the topics discussed by the various chapters: with the notions of the property of unpredictability of cities as complex systems (Batty), the major transitions (Marshall and Green), the order parameter, slaving principle, fluctuations and chaos of the synergetic cities (Portugali and Haken), the evolution of cities and their internal structure (Allen), with complexity and fractal cities (Frankhauser), the absence of cybernetic systems in cities (Gershenson, Santi and Ratti), the logical and emotional dimensions of human responses (Penn), the effects on mobility in cities (Verbavatz and Barthelemy), on risk and uncertainty in urban planning (Moroni and Chiffi) and the use of nudging as a planning tool that affects citizens behavior (Bandsma, Rauws and De Roo).

\section{REFERENCES}

Alexander, C. (1965), 'A city is not a tree', Architectural Forum, 122, pt 1 (1), 58-62, pt 2 (2), 58-62.

Alexander, C. (2002-4), The Nature of Order, 4 vols, Berkeley, CA: Center for Environmental Structure.

Alexander, C., S. Ishikawa and M. Silvestein (1977), A Pattern Language, New York: Oxford University Press.

Auerbach, F. (1913), 'Das Gesetz der Bevölkerungskonzentration', Petermanns Geographische Mitteilungun, 59, 74-6.

Barabási, A.-L. (2002), Linked: How Everything Is Connected to Everything Else, New York: Plume.

Bénard, H. (1900), 'Les tourbillons cellulaires dans une nappe liquid', Révue Générale des Sciences Pures et appliquées, 11, 1261-71, 1309-28.

Bergeson, H. (1911), Creative Evolution, 1998 trans. A. Mitchell, New York: Dover.

Bertallanffy, L. von (1968), General System Theory: Foundations, Development, Applications, New York: George Braziller.

Chadwick, G. (1971), A System View of Planning, Oxford: Pergamon Press.

Christaller, W. (1933), Central Places in Southern Germany, repr. 1966, Englewood Cliffs, NJ: Prentice Hall.

Einstein, A. (1917), 'Zur Quantentheorie der Strahlung', Physikalische Zeitschrift, 18, 121-8.

Friston, K. (2010), 'The free-energy principle: a unified brain theory?', Nature Reviews Neuroscience, 11 (2), 127-38.

Geddes, P. (1915), Cities in Evolution: An Introduction to the Town Planning Movement and to the Study of Civics, London: Williams.

Haken, H. and J. Portugali (2021), Synergetic Cities: Information, Steady State and Phase Transition. Implications to Urban Scaling, Smart Cities and Planning, Berlin, Heidelberg and New York: Springer Nature.

Hillier, B. (1996), Space is the Machine: A Configurational Theory of Architecture, Cambridge: Cambridge University Press.

Hillier, B. (2009), 'The city as a socio-technical system: a spatial reformulation in the light of the levels problem and the parallel problem', in S. Müller Arisona, G. Aschwanden, J. Halatsch and P. Wonka (eds), Digital Urban Modelling and Simulation, Berlin: Springer, pp. 24-48.

Huizinga, J. (1949), Homo Ludens: A Study of the Play-Element of Culture, London, Boston, MA, and Henley: Routledge \& Kegan Paul.

Jacobs, J. (1961), The Death and Life of Great American Cities, New York: Random House.

Lynch, K. (1960), The Image of the City, Cambridge, MA: MIT Press.

McLoughlin, J.B. (1969) Urban and Regional Planning: A System Approach, London: Faber and Faber.

Nicolis, G. and I. Prigogine (1977), Self-organization in Nonequilibrium Systems, New York: Wiley.

Portugali, J. (1985), 'Parallel currents in the natural and social sciences', in J. Portugali (ed.), Links Between Natural and Social Sciences, special issue of Geoforum, 16 (2), 227-38.

Portugali, J. (2011), Complexity, Cognition and the City, Berlin, Heidelberg and New York: Springer.

Pumain, D. (2009), 'L'espace, médium d'une construction spiralaire de la géographie, entre société et environnement', in B. Walliser (ed.), La cumulativité des connaissances en sciences sociales, Paris: EHESS, pp. 163-97. 
Reynaud, J. (1841), 'Villes', Encyclopédie nouvelle, vol. 7, Paris: Gosselin, pp. 670-87.

Smith, J.M. and E. Szathmary (1997), The Major Transitions in Evolution, Oxford: Oxford University Press.

Watts, D.J. (2004), 'The "new” science of networks', Annual Review of Sociology, 30 (August), 243-70.

Weaver, W. (1948), 'Science of complexity', American Scientist, 36 (4), 536-44.

Wiener, N. (1948), Cybernetics; or, Control and Communication in the Animal and the Machine, New York: Wiley and Sons.

Wittgenstein, L. (1953), Philosophical Investigations, trans. G.E.M. Anscombe, Oxford: Blackwell. 